Published in final edited form as:

Trends Immunol. 2018 April ; 39(4): 328-340. doi:10.1016/j.it.2018.02.003.

\title{
Innate Antiviral Immunity in the Skin
}

Chelsea Handfield ${ }^{1}$, Jeffery Kwock ${ }^{1}$, and Amanda S. MacLeod ${ }^{1,2,3}$

${ }^{1}$ Department of Dermatology, Duke University

${ }^{2}$ Department of Immunology, Duke University

${ }^{3}$ Pinnell Center for Investigative Dermatology

\begin{abstract}
Barrier sites such as the skin play a critical role in immune defense. They must maintain homeostasis with commensals and rapidly detect and limit pathogen invasion. This is accomplished in part through the production of endogenous antimicrobial peptides and proteins, which can be either constitutive or inducible. Here, we focus particularly on the control of innate antiviral proteins and present the basic aspects of their regulation in the skin by interferons, interferon-independent immunity, and environmental factors. We also discuss the activity and (dys-) function of antiviral proteins in the context of skin-tropic viruses and highlight the relevance of the innate antiviral pathway as a potential therapeutic avenue for vulnerable patient populations and skin diseases with high risk for virus infections.
\end{abstract}

\section{The Skin Barrier and Antiviral Defense}

The skin is the largest epithelial surface for interaction with microbes including viruses, bacteria, and fungi, and serves as the initial barrier to prevent pathologic microorganism entry into the body. Upon perturbation of the skin barrier, the delicate interactions between the cutaneous commensal microbiome and skin are interrupted and pathologic microorganisms, including viruses, have the potential to invade and infect this tissue. Clinical evidence demonstrates that viruses play a critical role in severe skin diseases and infections. The field of cutaneous innate antiviral immunity has been investigated in the setting of viral recognition and entry receptors, viral evasion mechanisms, as well as mastcell mediated antiviral immunity and inflammasome activation, topics which are summarized in excellent reviews elsewhere [1-4]. Here, we provide an overview of antiviral proteins, the protagonists of the innate immune system, that defend the body against foreign viral invaders. We review the current literature and discuss the myriad of mechanisms involved in regulation and function of antiviral proteins in the skin. We discuss and translate the significance of cutaneous antiviral immunity to vulnerable patient populations that are particularly susceptible to viral infection, including the newborns and the elderly, the

"Correspondence: amanda.macleod@duke.edu (A.S. MacLeod, nèe Büchau).

Publisher's Disclaimer: This is a PDF file of an unedited manuscript that has been accepted for publication. As a service to our customers we are providing this early version of the manuscript. The manuscript will undergo copyediting, typesetting, and review of the resulting proof before it is published in its final citable form. Please note that during the production process errors may be discovered which could affect the content, and all legal disclaimers that apply to the journal pertain. 
immune-compromised, and patients afflicted with atopic dermatitis, who can suffer from very severe viral skin infections, ultimately leading to systemic illness. Gaining insights into antiviral proteins and their mechanisms to regulate cutaneous viruses may offer insights into new and possibly less toxic therapeutic antiviral treatments.

\section{Regulation of Antiviral Proteins by the Cutaneous Immune Cell Network}

Antiviral proteins are host effector molecules that directly antagonize viral infections. There is abounding diversity in antiviral proteins in terms of their viral targets and mechanism of action (Table 1). Additionally, individual antiviral proteins may exhibit multiple antiviral actions depending on the tissue or cell type in which they are expressed or the virus against which they are acting. Host antiviral proteins that have demonstrated antiviral actions within cells present temporarily or permanently present in the skin (see Glossary) and/or are active against skin-tropic viruses are listed in Table 1. One of these antiviral proteins is oligoadenylate synthetase s (OAS2), which identifies viruses through binding of viral dsRNA and activating latent RNase (RNase L), which subsequently leads to the degradation of viral RNA [12]. OAS proteins can also function through an RNase L-independent mechanism [13] Within the skin, antiviral proteins, such as OAS family members, myxovirus resistance proteins (MX) GTPases, and Interferon-stimulated gene 15 (ISG-15) are expressed in various cell types. Previously published reports, and unpublished analyses of microarray, RNA-Seq, and single cell RNA-seq data sets reveal that antiviral proteins are expressed in epidermal keratinocytes, dendritic cells, and cutaneous T cell subsets [5-7]. Because it is well known that viruses intially infect only few basal keratinocytes within the epidermis but spare the more differentiated layers, future research is needed to define the temporal-spatial presence of antiviral proteins and how this guides the protection against viral skin infections.

The regulation and induction of antiviral proteins occurs in two phases. The early phase involves the direct recognition of viral nucleic acids, a type of pathogen-associated molecular pattern (PAMP), via pattern-recognition receptors (PRRs) including toll-like receptors (TLRs), melanoma differentiation associated gene 5 (MDA5), retinoic acidinducible gene (RIG-I), and cGAMP synthase (cGAS)[1]. TLR3, TLR7, and TLR9 detect viral nucleic acids and are expressed by a variety of skin cell types including keratinocytes, melanocytes, Langerhans cells, and dermal dendritic cells. Signaling through such PRRs induces interferons (IFNs) and pro-inflammatory responses (Figure 1, Key Figure). The vast majority of antiviral proteins are induced and amplified by IFNs. Yet, recent studies also highlight the ability for IFN-independent factors including IL-27 and additional factors, to induce the antiviral protein OAS2 in human epithelial keratinocytes and is discussed in a later paragraph [7].

There are three classes of IFNs distinguished by the receptor complex through which they signal. Type I IFNs (IFNa and $-\beta$ ) signal through the IFNAR complex, which is a heterodimer of IFNAR1 and IFNAR2. Type II IFN $\gamma$ signals through IFNGR. Type III IFN $\lambda$ signals through the IFNLR1 and IL-10R2 complex, which is almost exclusively expressed by epithelial cells [8]. The other IFN receptors are present ubiquitously. Through the secretion of IFNs, the antiviral response is amplified in the later phase as hundreds of IFN- 
stimulated genes (ISG) including antiviral proteins are activated. Within the cytoplasm, IFN signaling pathways produce complexes containing IRF9, STAT1 and STAT2 and homodimers of STAT1 that are capable of translocating into the nucleus to bind to enhancer elements to stimulate the transcription of target genes. The STAT1/STAT2/IRF9 complex binds to an interferon-sensitive response element (ISRE) within the promoter region of ISG15, Mx, OAS, and PKR genes whereas STAT1 homodimers bind to GAS elements within the promoter region of other ISGs (Figure 1). However, excessive and prolonged expression of type I IFNs is pathological and uncontrolled production of type I IFNs is associated with inflammatory disease and autoimmunity [9].

There are also emerging interferon-independent pathways that induce the production of antiviral proteins. In the skin, IL-27 stimulates the production of the antiviral protein OAS2 in human keratinocytes, but not antibacterial human beta defensin-2 (hBD2) and regenerating family member 3 alpha (REG3A) [7]. The underlying signaling pathways of IL-27-induced antiviral protein induction in skin cells is an area of active research. IL-27 is produced following cutaneous injury by murine $\mathrm{CD} 301 \mathrm{~b}^{+}$dermal dendritic cells and can be induced by dsRNA [7] (Figure 2). In addition, IRF-3 can also induce the production of antiviral proteins directly, independent of IFN signaling [10] (Figure 1). IRF-3 triggers the expression of antiviral IFIT1 and IFIT2 and to a smaller degree GBP1, OAS proteins, and ISG15 in T cells by binding to a region within their promoter gene homologous to their ISREs [11]. Furthermore, C11orf83, a component of complex III of the electron transport chain on the mitochondrial inner membrane, endows cells with a stronger capability to inhibit viral replication via the OAS3/RNAseL activity [12]. The IFN-independent pathways that produce antiviral proteins are of exceeding interest as they can offer insight into novel antiviral treatments, which would be a desired alternative to conventional antiviral therapies that have toxicity-associated side effects. Yet, whether these latter IFN-independent pathways, IRF3 and C11orf83, play relevant roles in antiviral protein regulation in the skin requires further investigation.

\section{Skin conditions and patient populations that relay susceptibility or resistance to virus infections}

Many viruses can infect skin cells or can be transmitted via the skin and can be causative for skin and/or systemic disease (Table 2). Notably, there is the notion of vulnerable patient populations that are at increased risk to become infected by viruses. These patients may have a loss, lack or suppression of antiviral proteins and enhancing their innate antiviral immunity may make them less susceptible to viral infections and provide a basis for the development of new antiviral therapeutics.

\section{Neonates and the elderly: antiviral immunity at extremes of age}

Two populations that show dramatically increased susceptibility to cutaneous viral infections are the neonates and the elderly.

Herpes simples virus (HSV) can cause particularly severe infections in neonates, possibly due to a weak antiviral response. The vast majority of neonatal herpes cases are acquired 
through vaginal delivery; in many instances from asymptomatic moms who were unaware they were carrying HSV. Thirty percent of neonatal herpes cases spread to the central nervous system and $25 \%$ of cases cause disseminated infection affecting multiple organs [13].

The microbiome is strongly influenced by external factors and at birth neonates transition from the wet in utero environment to the external world. Within the first few weeks after delivery, the skin of neonates is dominated by Firmicutes and other species, and only over the span of one year do children establish a cutaneous bacterial microbiome ('bacteriome') that is dominated by species one would expect to find in adults [14]. In addition to the bacteriome, fungi and even parasites live on/in the skin [15-19] and it is attractive to speculate that these may also regulate the virome and associated antiviral proteins in the skin. Similar observations have been recently made in the intestine and in additional barrier organs (review on this topic by Robinson and Pfeiffer, 2014 [20]). In mice and humans, a diverse cutaneous microbiome, mostly studied as the bacteriome, was found to positively regulate the immune response within the skin [18, 21-23]. We postulate that the cutaneous virome at the neonatal stage in life is undoubtedly unique. Therefore, given that the skin barrier is not fully fortified $[14,24]$ and the cutaneous virome is likely immature as well, two key factors in creating a strong innate immune response, it is possible that the neonatal antiviral innate immune system is underdeveloped, accounting for the increased susceptibility to severe forms of cutaneous viral infections in this population. Important open questions in the field are whether neonatal bacterial colonization co-regulates cutaneous viruses and/or whether viral colonization controls epidermal barrier function, tolerance mechanisms, or even drives the innate antiviral protein development in the skin $[22,25]$. In neonates suffering from atopic eczema, also called atopic dermatitis, the risk of HSV infection is even higher and this aspect is discussed in a later paragraph within this review article. In conclusion, if the cutaneous innate antiviral response could be enhanced in neonates at risk for HSV, these infants may not succumb to this grave HSV-induced systemic illness.

On the side of the spectrum, elderly often succumb to infections with varicella zoster virus (VZV), which is closely related to HSV. After a primary infection (causing chicken pox), VZV remains in a dormant state in the nervous system of infected patients and tends to reactivate in patients as they age producing the herpes zoster, also known as shingles rash. While the increased risk of cutaneous viral infections in neonates is likely due to an immature innate antiviral system, the increased susceptibility to viral infections in older individuals may be secondary to a reduced ability to mount an antiviral response within the innate and adaptive immune systems, a process often referred to immunosenescence [26]. Blood monocytes from older individuals and younger adults have shown no significant difference in transcriptional and functional levels of cytokines at baseline. However, when stimulated with nucleic acids, monocytes from older individuals have reduced TLR and RIG-I signaling and decreased transcription and expression of interferons, IFN-associated signaling molecules and antiviral proteins compared to younger adults [27] [28]. While several studies determined that cutaneous immune cells, such as keratinocytes, Langerhans cells, and skin $\mathrm{T}$ cells, also undergo age-related changes and demonstrate a senescent 
phenotype [29-35], identification and systematic analysis of innate antimicrobial effector molecules and antiviral proteins or their regulators, is missing.

\section{Antiviral defense in the context of inflammatory skin disease: Psoriasis and Atopic Dermatitis}

Psoriasis and atopic dermatitis (AD) are the two most common chronic inflammatory skin diseases. However, unlike patients psoriasis, $\mathrm{AD}$ is associated with a relative higher susceptibility to cutaneous viral infections. Interestingly, compared to psoriasis patients, AD patient skin is relatively deficient in professional antiviral proteins, such as OAS2, MX proteins, ISG15 and other antiviral proteins, Notably, increased antiviral protein expression appeared specific to the skin and was not observed in PBMCs, suggesting that a local factor contributes to antiviral protein expression [5, 37].

A key component of the psoriasis is the proliferation and survival of type $17 \mathrm{~T}$ helper (Th17) cells promoted by the cytokine IL-23 [36]. Imiquimod, an agonist of TLR7, is commonly used in murine studies to model a psoriasis-like disease state. In addition, in mice, the production of IL-23 and development of psoriasis-like skin disease is inducible by the binding of 5 triphosphate dsRNA to RIG-I [37]. IL-23 induces Th17 cells to release IL-29, a type III interferon (IFN $\lambda$ ) that stimulates the secretion of antiviral proteins Mx1, ISG15, and OAS2 from psoriatic keratinocytes [5]. Unsurprisingly, there is increased expression of antiviral genes ISG15, IRF7, and Mx2 in psoriatic skin [38]. Further, psoriasis susceptibility genes IFIH1 and DDX58 encode for the nucleic acid sensors MDA5 and RIGI respectively [39], while another susceptibility gene $R N F 114$ alters the regulation of MDA5 and RIG-I signaling [40]. While there is no clear evidence for a viral pathogenesis for psoriasis, it has been demonstrated that overt recognition of nucleic acids in complex with antimicrobial peptide LL-37 can trigger an innate antiviral immune response characteristic for psoriasis [41].

Atopic dermatitis (AD) is the most common allergic skin disease in the general population worldwide, especially in the newborn population (up to 15-30\%). AD is characterized by itchy, dry, and eczematous skin lesions with eosinophilic inflammatory infiltrates and spongiosis (intra-epidermal and intercellular edema). AD patients are at relatively higher risk for viral infections, including eczema herpeticum (caused by HSV-1), eczema vaccinatum (caused by vaccinia virus), eczema coxsackium (Coxsackie virus), and Molluscum contagiosum.

HSV is a dsDNA neurotropic virus that infects (muco-)cutaneous epithelium and is a member of the Herspesviridae family. In can cause eczema herpticum, a particularly debilitating cutaneous HSV infection in patients with AD. Notably, mucosal HSV infection in non AD-individuals induces types I and III IFN responses [42], producing OAS2, OAS3, MxA, and double-stranded RNA-activated protein kinase (PKR) [43, 44]. MxA reduces the replication of HSV-1 in primary human fibroblasts [45]. Interestingly however, in the absence of IFNa signaling, an alternatively spliced isoform of MxA is induced in infected cells that translocates to the nucleus and actually enhances HSV-1 replication [45]. The antiviral protein PKR stimulates autophagy of HSV [44] and murine embryonic fibroblasts deficient in PKR show increased susceptibility to HSV-1 [46]. Unsurprisingly, HSV-1 
protein ICP34.5 counters PKR activity by inhibiting IRF3 activation to prevent the translational shutdown induced by PKR [47]. This also illustrates the important role of IRF3, which was found to induce antiviral proteins IFIT1, IFIT2, ISG15, OAS, and GBP1 in the context of an HSV infection [48]. Recently, it was discovered that silencing IL-36 $\beta$ in mice produced more severe HSV-1 cutaneous disease, but the mechanism through which this cytokine exerts its effect has yet to be discovered [49].

Eczema herpeticum caused by HSV-1, is one of the most common viral infections in AD patients and this skin infection may progress to systemic infection and can be complicated by fever, malaise, kerato-conjunctivitis, encephalitis, and septic shock. Patients with eczema herpeticatum tend to have early-onset $\mathrm{AD}$, more severe disease, increased risk of asthma, increased allergen sensitization, dysbiosis and $S$. aureus colonization, and increased Th2 polarity. Notably, a null mutation in a gene critical for the skin barrier, called Filaggrin (FLG), is not only one of the strongest genetic predictors of $\mathrm{AD}$, but it confers an even greater risk for eczema herpeticum in AD patients[50], suggesting a pivotal role for a defective skin barrier in this devastating condition. Further risk factors include prior exposure to HSV-1 [51], genetic variants in IRF2 that produce an abnormal response to HSV, low expression of IFNAR1, and low expression or genetic variants of IFN $\gamma$ and/or IFNGR1 [52, 53]. All of these variants implicate some aspect of the innate antiviral system in the development of a very serious complication, eczema herpeticum, in patients with AD.

A hallmark of IgE-mediated diseases is an increased production of IL-4 and IL-13 by type 2 T helper (Th2) cells. Indeed, AD lesions within the skin show increased expression of Th2 cytokines IL-4 and IL-13. These cytokines have been shown to reduce the expression of antimicrobial proteins human beta defensin-3 (hBD3) and cathelicidin (LL-37) [54]. HBD3 and cathelicidin have been most commonly associated with their antibacterial functions, yet they also exhibit antiviral activity $[55,56]$. Decreased expression of 'professional' antiviral genes in the skin of patients with $\mathrm{AD}$ compared to normal, healthy skin and compared to psoriasis skin has also been noted [38, 52, 57-59], however it has not determined whether Th2 type cytokines suppress antiviral proteins. Nonetheless, given the results of psoriatic inflammation-associated upregulation of multiple antiviral proteins and a Th2 dominance in AD coupled with structural barrier defects and relative low antiviral protein expression, establishes the concept that the disease state of $\mathrm{AD}$ and the associated immune response and barrier dysfunction may negatively regulate the innate antiviral immune system (Figure 2).

Interestingly and linked to the dysfunctional barrier of AD skin, the propensity for Staph. aureus cutaneous infection is very high [60,61]. Importantly, Staph. aureus can cause disease flares and is itself a contributor to cutaneous viral infections seen in patients with AD [60, 62]. Alpha-toxin, a Staph. aureus virulence factor, enhances HSV-1 and Vaccinia virus (VACV) gene expression in human keratinocytes by forming pores that facilitate viral entry into cells [63]. How does Staphylococcus aureus, a skin commensal with high pathogenic potential $[23,64-66]$ affect antiviral protein production, associated skin inflammation, and wound healing responses? If Staph. aureus can block antiviral protein production this may contribute further to increased infection risk and may be therapeutically prevented by antimicrobial treatments. We also do not understand how barrier dysfunction caused by $F L G$ mutations or mechanical perturbation, pain- and itch-associated 
neurotransmitters related to itch behavior and Staph. aureus infection [67-69] in AD patients relates to the regulation of genes encoding antiviral proteins. This knowledge may help target and prevent viral infections in the highly susceptible AD population.

Vaccinia virus (VACV) is the second most common cause of cutaneous viral infections in patients with AD. VACV is a member of the Poxviridae family of dsDNA viruses that primarily infect cells within the skin including keratinocytes, Langerhans cells, other dendritic cells, and macrophages. These viruses cause a range of diseases from molluscum contagiosum to severe systemic disease such as smallpox (Table 2). Molluscum contagiosum presents as a more severe and/or treatment-resistant rash in children with $\mathrm{AD}$ and in immunocompromised patients [70, 71]. Clinically, VACV is used as a vaccine to prevent smallpox. Intuitively, major complications of this vaccine have occured at a higher rate in virus susceptible populations. For example, patients with $\mathrm{AD}$ are more likely to develop vaccinia vaccinatum, while immunocompromised patients are more likely to develop progressive vaccinia [72-74]. The modified vaccine virus Ankara (MVA) produces type I IFNs in mouse conventional dendritic cells through the cGAS/STING pathway [75]. VACV infection of human keratinocytes induces the production of Th2 cytokines [76], which again reduce the expression of antimicrobial peptides. Keratinocytes sense VACV DNA via TLR7 and stimulate the production of type I and II IFNs [77]. However, upon entry into host cells, vaccinia counters the recognition of viral DNA via TLR7 by producing the inhibitor protein E3. E3 also inhibits PKR, ISG15 and prevents Langerhans cells from presenting viral antigens to $\mathrm{T}$ cells [77-80].

\section{The immunocompromised patient}

Immunosuppression is an almost universal strategy to prevent rejection following solidorgan transplantation. These immunocompromised patients have an exceedingly high risk of developing non-melanoma squamous cell carcinoma (NMSC), possibly in part through a viral pathway. While this data does not provide evidence for a causative relationship, a metaanalysis demonstrated that squamous cell carcinoma (SCC) lesions from immunocompromised patients were three times more likely to express human papilloma virus (HPV) than SCC lesions from immunocompetent patients [81]. HPV is a small, nonenveloped dsDNA virus that is a member of the Papillomavirus family. It is a member of the commensal skin microbiome [16], but also a causative agent for warts and subsets of squamous cell carcinoma. It preferentially infects basal epithelial cells but only produces virions in the terminally differentiated upper layers of the epithelium [82]. IFIT1 is able to bind to and sequester HPV's viral helicase E1 within the cytoplasm. This action prevents the viral protein from entering the nucleus to join its replication complex [83, 84]. The signaling events upstream of IFIT1 in relation to HPV are unknown. IFIT1 is typically induced by type I IFNs but type I IFNs may or may not be implicated in the antiviral response to HPV. One study demonstrated that type I IFNs reduced the replication of HPV16 [85]. However a subsequent in vitro study demonstrated that in human keratinocytes type II IFN $\gamma$ and not type I IFNa/ $\beta$ inhibited an array of HPV strains through a JAK2/STAT1 pathway [86]. IFIT1 is also known to be activated independent of type I IFNs via IRF3, but IRF3 does not have the capability to bind to the HPV16 proteins and thus was associated with a downregulation of the antiviral genes it typically induces including IFIT1, IFIT2, OAS, and GBP1 [11]. 
Therefore there is possibly another type I IFN-independent pathway through which IFIT1 is produced. In contrast, IFITM proteins 1, 2, and 3 were found to moderately enhance HPV-16 replication in keratinocytes [87]. A deeper understanding of how antiviral proteins are regulated in the skin and how they affect HPV infection and virion generation will ultimately provide knowledge about the cellular and molecular mechanisms underlying innate antiviral immunity against HPV in keratinocytes. Such knowledge is relevant because HPV amplifies its genome dependent on keratinocyte differentiation [82]. Research defining how differentiation and cell cycle arrest regulates antiviral proteins and how viruses usurp the innate immunity machinery within infected keratinocytes to counteract antiviral defenses is of interest to immunologists, virologists, and dermatologist alike.

Immunosuppressed patients, as well as older, and/or chronically sun-exposed patients furthermore bear a higher risk for infection with Merkel Cell Polyomavirus (MCP). Yet, MCP is part of the healthy human virome [16, 60]. After MCP's discovery just less than a decade ago, it has been demonstrated that viral oncoproteins of MCP play a critical role in Merkel Cell Carcinoma (MCC) progression and are found in the majority of MCC tumors. Importantly, while the adaptive immune response against MCP is well established, and involves T cells that recognize a specific MCP-epitope [88], the control of MCP by innate antiviral proteins has not been studied and may uncover novel and new insight into the innate immune response to this virus.

\section{Concluding Remarks}

The skin barrier faces a multitude of insults and the innate immune system defends the body by preventing pathologic microorganism invasion. Great progress has been achieved in regards to understanding the mechanisms of antibacterial proteins, such as defensins and cathelicidins, however much has yet to be discovered regarding professional antiviral proteins, especially within the skin (see Outstanding Questions). The extremely common chronic inflammatory skin diseases atopic dermatitis and psoriasis are associated with an altered and opposite susceptibility to viral infections, which is directly related to the level of expression of antiviral proteins within these skin lesions. The young, the elderly, and immunocompromised patients are vulnerable subsets of the population facing increased susceptibility to cutaneous viral infections for diverging reasons. Furthermore, many viruses, including emerging Zika, Dengue, and West Nile viruses are transmitted into the skin via mosquito bites, and can infect skin cells [6, 82, 89-92]. It is therefore important to have an understanding of the regulators of antiviral host defense within the cutaneous epithelium and cutaneous immune cells to comprehend viral disease pathogenesis and ultimately develop new preventative and therapeutic treatments (Figure 2, key Figure). The current antiviral treatments are associated with severe toxicities including nephrotoxicity and neurotoxicity, however antiviral therapies that target antiviral proteins or effectors along the innate antiviral signaling cascade may minimize toxicity and resistance. Therefore, enhancing the discussion of antiviral proteins, which provide a critical service to the skin barrier, offers new insights into human disease. 


\section{Outstanding Questions Box}

- Does the cutaneous microbiome contribute to innate antiviral immunity?

- What type of interferon-independent pathways exist to induce the transcription of antiviral proteins?

- What is the relative contribution of these interferon-independent and dependent pathways to antiviral protein expression in homeostatic conditions? And in inflammation settings? What are the essential and collaborative factors in establishing antiviral immunity in the skin?

- What is the interplay between antiviral proteins and other barriers of the skin (for example physical and chemical) in this process?

\section{Acknowledgments}

The authors would like to thank Shiz Aoki (BioRender, Inc.) for help creating figure illustrations. The authors would like to apologize to all investigators whose work could not be cited here due to space constraints. This work was funded in part by the Poindexter Scholars in Basic Science (to C.H.), Stead Scholarship (to J.K), the Duke Physician-Scientist Strong Award (to A.S.M.), NIH R21 AI128727 (to A.S.M.), NIH K08 AR063729 (to A.S.M.), and the Dermatology Foundation Award (to A.S.M.). A.S.M. also receives financial support from Silab.

\section{Glossary}

\section{Immunosenescence}

age-related decline of the immune system

\section{Langerhans cells}

subset of dendritic cells present in the epithelium

NFKB

transcription factor that regulates the immune response to infection

\section{Neurotropic virus}

virus that infects nerve cells

\section{Skin}

the skin is composed of two layers, the superficial epidermis, which is home to keratinocytes, Langerhans cells, and melanocytes, and the underlying dermis, which contains other immune cells and connective tissue

\section{Tetratricopeptide repeats}

degenerate 34 amino acid motif that mediate protein-protein interactions

\section{Type 2 T helper (Th2) cells}

subset of $\mathrm{CD}^{+}{ }^{+} \mathrm{T}$ cells, which produce the cytokines IL-4, IL-5, IL-10, and IL-13

\section{Type $17 \mathrm{~T}$ helper (Th17) cells}

subset of $\mathrm{CD} 4^{+} \mathrm{T}$ cells, which produce the cytokine IL-17 


\section{Virulence factor}

molecules secreted by microorganisms that enhance their infectivity

\section{References}

1. Chan YK, Gack MU. Viral evasion of intracellular DNA and RNA sensing. Nat Rev Microbiol. 2016; 14(6):360-73. [PubMed: 27174148]

2. Iwasaki A. Exploiting Mucosal Immunity for Antiviral Vaccines. Annu Rev Immunol. 2016; 34:575-608. [PubMed: 27168245]

3. Urb M, Sheppard DC. The role of mast cells in the defence against pathogens. PLoS Pathog. 2012; 8(4):e1002619. [PubMed: 22577358]

4. Paludan SR, et al. Recognition of herpesviruses by the innate immune system. Nat Rev Immunol. 2011; 11(2):143-54. [PubMed: 21267015]

5. Wolk K, et al. IL-29 is produced by $\mathrm{T}(\mathrm{H}) 17$ cells and mediates the cutaneous antiviral competence in psoriasis. Sci Transl Med. 2013; 5(204):204ra129.

6. Surasombatpattana $\mathrm{P}$, et al. Dengue virus replication in infected human keratinocytes leads to activation of antiviral innate immune responses. Infect Genet Evol. 2011; 11(7):1664-73. [PubMed: 21722754]

7. Yang B, et al. IL-27 Facilitates Skin Wound Healing through Induction of Epidermal Proliferation and Host Defense. J Invest Dermatol. 2017; 137(5):1166-1175. [PubMed: 28132857]

8. Wack A, Terczynska-Dyla E, Hartmann R. Guarding the frontiers: the biology of type III interferons. Nat Immunol. 2015; 16(8):802-9. [PubMed: 26194286]

9. Hall JC, Rosen A. Type I interferons: crucial participants in disease amplification in autoimmunity. Nat Rev Rheumatol. 2010; 6(1):40-9. [PubMed: 20046205]

10. Noyce RS, et al. Membrane perturbation elicits an IRF3-dependent, interferon-independent antiviral response. J Virol. 2011; 85(20):10926-31. [PubMed: 21813605]

11. Grandvaux N, et al. Transcriptional profiling of interferon regulatory factor 3 target genes: direct involvement in the regulation of interferon-stimulated genes. J Virol. 2002; 76(11):5532-9. [PubMed: 11991981]

12. Yang Y, et al. Mitochondrial C11 orf83 is a potent Antiviral Protein Independent of interferon production. Sci Rep. 2017; 7:44303. [PubMed: 28418037]

13. Knezevic A, et al. Disseminated neonatal herpes caused by herpes simplex virus types 1 and 2 . Emerg Infect Dis. 2007; 13(2):302-4. [PubMed: 17479897]

14. Capone KA, et al. Diversity of the human skin microbiome early in life. J Invest Dermatol. 2011; 131(10):2026-32. [PubMed: 21697884]

15. Grice EA, Segre JA. Interaction of the microbiome with the innate immune response in chronic wounds. Adv Exp Med Biol. 2012; 946:55-68. [PubMed: 21948362]

16. Hannigan GD, et al. The human skin double-stranded DNA virome: topographical and temporal diversity, genetic enrichment, and dynamic associations with the host microbiome. MBio. 2015; 6(5):e01578-15. [PubMed: 26489866]

17. Hannigan GD, et al. Evolutionary and functional implications of hypervariable loci within the skin virome. PeerJ. 2017; 5:e2959. [PubMed: 28194314]

18. Kong HH, et al. Temporal shifts in the skin microbiome associated with disease flares and treatment in children with atopic dermatitis. Genome Res. 2012; 22(5):850-9. [PubMed: 22310478]

19. Nakatsuji T, et al. The microbiome extends to subepidermal compartments of normal skin. Nat Commun. 2013; 4:1431. [PubMed: 23385576]

20. Robinson CM, Pfeiffer JK. Viruses and the Microbiota. Annu Rev Virol. 2014; 1:55-69. [PubMed: 25821837]

21. Naik S, et al. Compartmentalized control of skin immunity by resident commensals. Science. 2012; 337(6098):1115-9. [PubMed: 22837383] 
22. Scharschmidt TC, et al. Commensal Microbes and Hair Follicle Morphogenesis Coordinately Drive Treg Migration into Neonatal Skin. Cell Host Microbe. 2017; 21(4):467-477 e5. [PubMed: 28343820]

23. Liu H, et al. Staphylococcus aureus Epicutaneous Exposure Drives Skin Inflammation via IL-36Mediated T Cell Responses. Cell Host Microbe. 2017; 22(5):653-666 e5. [PubMed: 29120743]

24. Nikolovski J, et al. Barrier function and water-holding and transport properties of infant stratum corneum are different from adult and continue to develop through the first year of life. J Invest Dermatol. 2008; 128(7):1728-36. [PubMed: 18200056]

25. Meisel JS, et al. Commensal microbiota modulate gene expression in the skin. Microbiome. 2018; 6(1):20. [PubMed: 29378633]

26. Pera A, et al. Immunosenescence: Implications for response to infection and vaccination in older people. Maturitas. 2015; 82(1):50-5. [PubMed: 26044074]

27. Metcalf TU, et al. Human Monocyte Subsets Are Transcriptionally and Functionally Altered in Aging in Response to Pattern Recognition Receptor Agonists. J Immunol. 2017; 199(4):14051417. [PubMed: 28696254]

28. Pillai PS, et al. Mx1 reveals innate pathways to antiviral resistance and lethal influenza disease. Science. 2016; 352(6284):463-6. [PubMed: 27102485]

29. Bacon P, Bodner B, Nickoloff BJ. Senescent human keratinocytes suppress colony formation of HeLa cells. J Dermatol Sci. 2005; 38(1):64-6. [PubMed: 15795126]

30. Chaturvedi V, et al. Role of INK4a/Arf locus-encoded senescent checkpoints activated in normal and psoriatic keratinocytes. Am J Pathol. 2003; 162(1):161-70. [PubMed: 12507899]

31. Chaturvedi V, et al. Apoptosis in proliferating, senescent, and immortalized keratinocytes. J Biol Chem. 1999; 274(33):23358-67. [PubMed: 10438513]

32. Perera RJ, et al. Defining the transcriptome of accelerated and replicatively senescent keratinocytes reveals links to differentiation, interferon signaling, and Notch related pathways. J Cell Biochem. 2006; 98(2):394-408. [PubMed: 16440318]

33. Bhushan M, et al. Tumour necrosis factor-alpha-induced migration of human Langerhans cells: the influence of ageing. Br J Dermatol. 2002; 146(1):32-40. [PubMed: 11841364]

34. Cumberbatch M, Dearman RJ, Kimber I. Influence of ageing on Langerhans cell migration in mice: identification of a putative deficiency of epidermal interleukin-1beta. Immunology. 2002; 105(4):466-77. [PubMed: 11985667]

35. Fisher GJ, et al. Molecular basis of sun-induced premature skin ageing and retinoid antagonism. Nature. 1996; 379(6563):335-9. [PubMed: 8552187]

36. Lowes MA, et al. The IL-23/T17 pathogenic axis in psoriasis is amplified by keratinocyte responses. Trends Immunol. 2013; 34(4):174-81. [PubMed: 23291100]

37. Zhu H, et al. RIG-I antiviral signaling drives interleukin-23 production and psoriasis-like skin disease. EMBO Mol Med. 2017; 9(5):589-604. [PubMed: 28377495]

38. Raposo RA, et al. Antiviral gene expression in psoriasis. J Eur Acad Dermatol Venereol. 2015; 29(10):1951-7. [PubMed: 25809693]

39. Tsoi LC, et al. Identification of 15 new psoriasis susceptibility loci highlights the role of innate immunity. Nat Genet. 2012; 44(12):1341-8. [PubMed: 23143594]

40. Bijlmakers MJ, et al. Functional analysis of the RNF114 psoriasis susceptibility gene implicates innate immune responses to double-stranded RNA in disease pathogenesis. Hum Mol Genet. 2011; 20(16):3129-37. [PubMed: 21571784]

41. Lande R, et al. Plasmacytoid dendritic cells sense self-DNA coupled with antimicrobial peptide. Nature. 2007; 449(7162):564-9. [PubMed: 17873860]

42. Ank N, et al. Lambda interferon (IFN-lambda), a type III IFN, is induced by viruses and IFNs and displays potent antiviral activity against select virus infections in vivo. J Virol. 2006; 80(9):45019. [PubMed: 16611910]

43. Sarkar SN, Sen GC. Novel functions of proteins encoded by viral stress-inducible genes. Pharmacol Ther. 2004; 103(3):245-59. [PubMed: 15464592]

44. Talloczy Z, Virgin HWt, Levine B. PKR-dependent autophagic degradation of herpes simplex virus type 1. Autophagy. 2006; 2(1):24-9. [PubMed: 16874088] 
45. $\mathrm{Ku} \mathrm{CC}$, et al. Herpes simplex virus-1 induces expression of a novel MxA isoform that enhances viral replication. Immunol Cell Biol. 2011; 89(2):173-82. [PubMed: 20603636]

46. Al-khatib K, et al. The murine double-stranded RNA-dependent protein kinase PKR and the murine $2^{\prime}, 5^{\prime}$-oligoadenylate synthetase-dependent RNase $\mathrm{L}$ are required for IFN-beta-mediated resistance against herpes simplex virus type 1 in primary trigeminal ganglion culture. Virology. 2003; 313(1):126-35. [PubMed: 12951027]

47. Verpooten D, et al. Control of TANK-binding kinase 1-mediated signaling by the gamma(1)34.5 protein of herpes simplex virus 1. J Biol Chem. 2009; 284(2):1097-105. [PubMed: 19010780]

48. Mossman KL, et al. Herpes simplex virus triggers and then disarms a host antiviral response. $\mathrm{J}$ Virol. 2001; 75(2):750-8. [PubMed: 11134288]

49. Milora KA, et al. Interleukin-36beta provides protection against HSV-1 infection, but does not modulate initiation of adaptive immune responses. Sci Rep. 2017; 7(1):5799. [PubMed: 28724920]

50. Gao PS, et al. Filaggrin mutations that confer risk of atopic dermatitis confer greater risk for eczema herpeticum. J Allergy Clin Immunol. 2009; 124(3):507-13. 513 e1-7. [PubMed: 19733298]

51. Xu F, et al. Trends in herpes simplex virus type 1 and type 2 seroprevalence in the United States. JAMA. 2006; 296(8):964-73. [PubMed: 16926356]

52. Leung DY, et al. Human atopic dermatitis complicated by eczema herpeticum is associated with abnormalities in IFN-gamma response. J Allergy Clin Immunol. 2011; 127(4):965, 73e1-5. [PubMed: 21458658]

53. Gao L, et al. Targeted deep sequencing identifies rare loss-of-function variants in IFNGR1 for risk of atopic dermatitis complicated by eczema herpeticum. J Allergy Clin Immunol. 2015; 136(6): 1591-1600. [PubMed: 26343451]

54. Hata TR, et al. History of eczema herpeticum is associated with the inability to induce human betadefensin (HBD)-2, HBD-3 and cathelicidin in the skin of patients with atopic dermatitis. Br J Dermatol. 2010; 163(3):659-61. [PubMed: 20545685]

55. Beck LA, et al. Phenotype of atopic dermatitis subjects with a history of eczema herpeticum. J Allergy Clin Immunol. 2009; 124(2):260-9. 269 e1-7. [PubMed: 19541356]

56. Ong PY, et al. Endogenous antimicrobial peptides and skin infections in atopic dermatitis. N Engl J Med. 2002; 347(15):1151-60. [PubMed: 12374875]

57. Bin L, et al. Specificity protein 1 is pivotal in the skin's antiviral response. J Allergy Clin Immunol. 2011; 127(2):430, 438 e1-2. [PubMed: 21208652]

58. Broccardo CJ, et al. Comparative proteomic profiling of patients with atopic dermatitis based on history of eczema herpeticum infection and Staphylococcus aureus colonization. J Allergy Clin Immunol. 2011; 127(1):186-93. 193 e1-11. [PubMed: 21211653]

59. Howell MD, et al. The signal transducer and activator of transcription 6 gene (STAT6) increases the propensity of patients with atopic dermatitis toward disseminated viral skin infections. $\mathrm{J}$ Allergy Clin Immunol. 2011; 128(5):1006-14. [PubMed: 21762972]

60. Byrd AL, et al. Staphylococcus aureus and Staphylococcus epidermidis strain diversity underlying pediatric atopic dermatitis. Sci Transl Med. 2017; 9(397)

61. Kobayashi T, et al. Dysbiosis and Staphylococcus aureus Colonization Drives Inflammation in Atopic Dermatitis. Immunity. 2015; 42(4):756-66. [PubMed: 25902485]

62. Hong SW, et al. An important role of alpha-hemolysin in extracellular vesicles on the development of atopic dermatitis induced by Staphylococcus aureus. PLoS One. 2014; 9(7):e100499. [PubMed: 24992681]

63. Bin L, et al. Staphylococcus aureus alpha-toxin modulates skin host response to viral infection. J Allergy Clin Immunol. 2012; 130(3):683-691 e2. [PubMed: 22840852]

64. Krishna S, Miller LS. Innate and adaptive immune responses against Staphylococcus aureus skin infections. Semin Immunopathol. 2012; 34(2):261-80. [PubMed: 22057887]

65. Malhotra N, et al. IL-22 derived from gammadelta T cells restricts Staphylococcus aureus infection of mechanically injured skin. J Allergy Clin Immunol. 2016; 138(4):1098-1107 e3. [PubMed: 27543072]

66. Ortines RV, et al. Neutralizing alpha-toxin accelerates healing of Staphylococcus aureus-infected wounds in normal and diabetic mice. Antimicrob Agents Chemother. 2018 
67. Blake KJ, et al. Staphylococcus aureus produces pain through pore-forming toxins and neuronal TRPV1 that is silenced by QX-314. Nat Commun. 2018; 9(1):37. [PubMed: 29295977]

68. Granstein RD, et al. Calcitonin gene-related peptide: key regulator of cutaneous immunity. Acta Physiol (Oxf). 2015; 213(3):586-94. [PubMed: 25534428]

69. Kashem SW, RM, Yao C, Honda CN, Vulchanova L, Kaplan DH. Nociceptive Sensory Fibers Drive Interleukin-23 Production from CD301b+ Dermal Dendritic Cells and Drive Protective Cutaneous Immunity. Immunity. 2015; 43(3):515-526. [PubMed: 26377898]

70. Dohil MA, et al. The epidemiology of molluscum contagiosum in children. J Am Acad Dermatol. 2006; 54(1):47-54. [PubMed: 16384754]

71. Euvrard S, et al. Skin diseases in children with organ transplants. J Am Acad Dermatol. 2001; 44(6):932-9. [PubMed: 11369903]

72. Howell MD, et al. Selective killing of vaccinia virus by LL-37: implications for eczema vaccinatum. J Immunol. 2004; 172(3):1763-7. [PubMed: 14734759]

73. Howell MD, et al. Cytokine milieu of atopic dermatitis skin subverts the innate immune response to vaccinia virus. Immunity. 2006; 24(3):341-8. [PubMed: 16546102]

74. Wollenberg A, Engler R. Smallpox, vaccination and adverse reactions to smallpox vaccine. Curr Opin Allergy Clin Immunol. 2004; 4(4):271-5. [PubMed: 15238792]

75. Dai $\mathrm{P}$, et al. Modified vaccinia virus Ankara triggers type I IFN production in murine conventional dendritic cells via a cGAS/STING-mediated cytosolic DNA-sensing pathway. PLoS Pathog. 2014; 10(4):e1003989. [PubMed: 24743339]

76. Liu L, et al. Vaccinia virus induces strong immunoregulatory cytokine production in healthy human epidermal keratinocytes: a novel strategy for immune evasion. J Virol. 2005; 79(12):7363-70. [PubMed: 15919891]

77. Deng L, et al. Vaccinia virus subverts a mitochondrial antiviral signaling protein-dependent innate immune response in keratinocytes through its double-stranded RNA binding protein, E3. J Virol. 2008; 82(21):10735-46. [PubMed: 18715932]

78. Deng L, et al. Vaccinia virus infection attenuates innate immune responses and antigen presentation by epidermal dendritic cells. J Virol. 2006; 80(20):9977-87. [PubMed: 17005676]

79. Chang HW, Watson JC, Jacobs BL. The E3L gene of vaccinia virus encodes an inhibitor of the interferon-induced, double-stranded RNA-dependent protein kinase. Proc Natl Acad Sci U S A. 1992; 89(11):4825-9. [PubMed: 1350676]

80. Eduardo-Correia B, et al. ISG15 is counteracted by vaccinia virus E3 protein and controls the proinflammatory response against viral infection. J Virol. 2014; 88(4):2312-8. [PubMed: 24257616]

81. Wang J, et al. Role of human papillomavirus in cutaneous squamous cell carcinoma: a metaanalysis. J Am Acad Dermatol. 2014; 70(4):621-9. [PubMed: 24629358]

82. Anacker DC, et al. HPV31 utilizes the ATR-Chk1 pathway to maintain elevated RRM2 levels and a replication-competent environment in differentiating Keratinocytes. Virology. 2016; 499:383-396. [PubMed: 27764728]

83. Saikia P, Fensterl V, Sen GC. The inhibitory action of P56 on select functions of E1 mediates interferon's effect on human papillomavirus DNA replication. J Virol. 2010; 84(24):13036-9. [PubMed: 20926571]

84. Terenzi F, Saikia P, Sen GC. Interferon-inducible protein, P56, inhibits HPV DNA replication by binding to the viral protein E1. EMBO J. 2008; 27(24):3311-21. [PubMed: 19008854]

85 . Herdman MT, et al. Interferon-beta treatment of cervical keratinocytes naturally infected with human papillomavirus 16 episomes promotes rapid reduction in episome numbers and emergence of latent integrants. Carcinogenesis. 2006; 27(11):2341-53. [PubMed: 16973673]

86. Day PM, et al. Interferon Gamma Prevents Infectious Entry of Human Papillomavirus 16 via an L2-Dependent Mechanism. J Virol. 2017; 91(10)

87. Warren CJ, et al. The antiviral restriction factors IFITM1, 2 and 3 do not inhibit infection of human papillomavirus, cytomegalovirus and adenovirus. PLoS One. 2014; 9(5):e96579. [PubMed: 24827144] 
88. Miller NJ, et al. Tumor-Infiltrating Merkel Cell Polyomavirus-Specific T Cells Are Diverse and Associated with Improved Patient Survival. Cancer Immunol Res. 2017; 5(2):137-147. [PubMed: 28093446]

89. Shu Q, et al. ADAP2 Is an Interferon Stimulated Gene That Restricts RNA Virus Entry. PLoS Pathog. 2015; 11(9):e1005150. [PubMed: 26372645]

90. Zhu X, et al. IFITM3-containing exosome as a novel mediator for anti-viral response in dengue virus infection. Cell Microbiol. 2015; 17(1):105-18. [PubMed: 25131332]

91. Zhang J, et al. Distinct expression of interferon-induced protein with tetratricopeptide repeats (IFIT) $1 / 2 / 3$ and other antiviral genes between subsets of dendritic cells induced by dengue virus 2 infection. Immunology. 2016; 148(4):363-76. [PubMed: 27135915]

92. Dai J, Pan W, Wang P. ISG15 facilitates cellular antiviral response to dengue and west nile virus infection in vitro. Virol J. 2011; 8:468. [PubMed: 21992229]

93. Clemens MJ, Williams BR. Inhibition of cell-free protein synthesis by pppA2 $2^{\prime} 5^{\prime} \mathrm{A} 2^{\prime} \mathrm{p} 5^{\prime} \mathrm{A}$ : a novel oligonucleotide synthesized by interferon-treated L cell extracts. Cell. 1978; 13(3):565-72. [PubMed: 657268]

94. Gao S, et al. Structure of myxovirus resistance protein a reveals intra- and intermolecular domain interactions required for the antiviral function. Immunity. 2011; 35(4):514-25. [PubMed: 21962493]

95. Liu Z, et al. The interferon-inducible MxB protein inhibits HIV-1 infection. Cell Host Microbe. 2013; 14(4):398-410. [PubMed: 24055605]

96. Fricke T, et al. MxB binds to the HIV-1 core and prevents the uncoating process of HIV-1. Retrovirology. 2014; 11:68. [PubMed: 25123063]

97. Li G, et al. The evolutionarily dynamic IFN-inducible GTPase proteins play conserved immune functions in vertebrates and cephalochordates. Mol Biol Evol. 2009; 26(7):1619-30. [PubMed: 19369598]

98. Biering SB, et al. Viral Replication Complexes Are Targeted by LC3-Guided Interferon-Inducible GTPases. Cell Host Microbe. 2017; 22(1):74-85 e7. [PubMed: 28669671]

99. Chesarino NM, et al. IFITM3 requires an amphipathic helix for antiviral activity. EMBO Rep. 2017; 18(10):1740-1751. [PubMed: 28835547]

100. Pichlmair A, et al. IFIT1 is an antiviral protein that recognizes $5^{\prime}$-triphosphate RNA. Nat Immunol. 2011; 12(7):624-30. [PubMed: 21642987]

101. Ilan L, et al. PKR activation and eIF2alpha phosphorylation mediate human globin mRNA splicing at spliceosome assembly. Cell Res. 2017; 27(5):688-704. [PubMed: 28374749]

102. Zhao C, et al. Human ISG15 conjugation targets both IFN-induced and constitutively expressed proteins functioning in diverse cellular pathways. Proc Natl Acad Sci U S A. 2005; 102(29): 10200-5. [PubMed: 16009940]

103. Anderson LJ. Role of parvovirus B19 in human disease. Pediatr Infect Dis J. 1987; 6(8):711-8. [PubMed: 2823211]

104. Spruance SL, et al. The natural history of recurrent herpes simplex labialis: implications for antiviral therapy. N Engl J Med. 1977; 297(2):69-75. [PubMed: 194157]

105. Gottlieb SL, Myskowski PL. Molluscum contagiosum. Int J Dermatol. 1994; 33(7):453-61. [PubMed: 7928025]

106. Allen AL, Siegfried EC. What's new in human papillomavirus infection. Curr Opin Pediatr. 2000; 12(4):365-9. [PubMed: 10943818]

107. Carr J, Gyorfi T. Human papillomavirus. Epidemiology, transmission, and pathogenesis. Clin Lab Med. 2000; 20(2):235-55. [PubMed: 10863639]

108. Feng $\mathrm{H}$, et al. Clonal integration of a polyomavirus in human Merkel cell carcinoma. Science. 2008; 319(5866):1096-100. [PubMed: 18202256]

109. Lapins J, et al. Skin and mucosal characteristics of symptomatic primary HIV-1 infection. AIDS Patient Care STDS. 1997; 11(2):67-70. [PubMed: 11361765]

110. Wu SJ, et al. Human skin Langerhans cells are targets of dengue virus infection. Nat Med. 2000; 6(7):816-20. [PubMed: 10888933] 
111. Zou S, et al. West Nile fever characteristics among viremic persons identified through blood donor screening. J Infect Dis. 2010; 202(9):1354-61. [PubMed: 20874087]

112. Derrington SM, et al. Mucocutaneous Findings and Course in an Adult With Zika Virus Infection. JAMA Dermatol. 2016; 152(6):691-3. [PubMed: 27168495]

113. Buchau AS, et al. Bcl-3 Acts as an Innate Immune Modulator by Controlling Antimicrobial Responses in Keratinocytes. J Invest Dermatol. 2009

114. Briant L, et al. Role of skin immune cells on the host susceptibility to mosquito-borne viruses. Virology. 2014; 464-465:26-32.

115. Hamel R, et al. Biology of Zika Virus Infection in Human Skin Cells. J Virol. 2015; 89(17):888096. [PubMed: 26085147]

116. Frumence E, et al. The South Pacific epidemic strain of Zika virus replicates efficiently in human epithelial A549 cells leading to IFN-beta production and apoptosis induction. Virology. 2016; 493:217-26. [PubMed: 27060565]

117. Brass AL, et al. The IFITM proteins mediate cellular resistance to influenza A H1N1 virus, West Nile virus, and dengue virus. Cell. 2009; 139(7):1243-54. [PubMed: 20064371]

118. Mayr L, Su B, Moog C. Langerhans Cells: the 'Yin and Yang' of HIV Restriction and Transmission. Trends Microbiol. 2017; 25(3):170-172. [PubMed: 28190635]

119. Nasr N, et al. HIV infection of dendritic cells. Methods Mol Biol. 2014; 1087:221-32. [PubMed: 24158826]

120. Kwan WH, et al. Dendritic cell precursors are permissive to dengue virus and human immunodeficiency virus infection. J Virol. 2005; 79(12):7291-9. [PubMed: 15919883]

121. Kawamura T, et al. The role of Langerhans cells in the sexual transmission of HIV. J Dermatol Sci. 2005; 40(3):147-55. [PubMed: 16226431]

122. Bomsel M, Ganor Y. Calcitonin Gene-Related Peptide Induces HIV-1 Proteasomal Degradation in Mucosal Langerhans Cells. J Virol. 2017; 91(23) 
Trends Box

- As the body's barrier organ exposed to the environment, the skin is constantly challenged by potentially harmful viruses

- Antiviral proteins are key effector molecules of the cutaneous innate host defense program

- Innate antiviral immune responses are inducible by interferon-dependent and interferon-independent mechanisms 


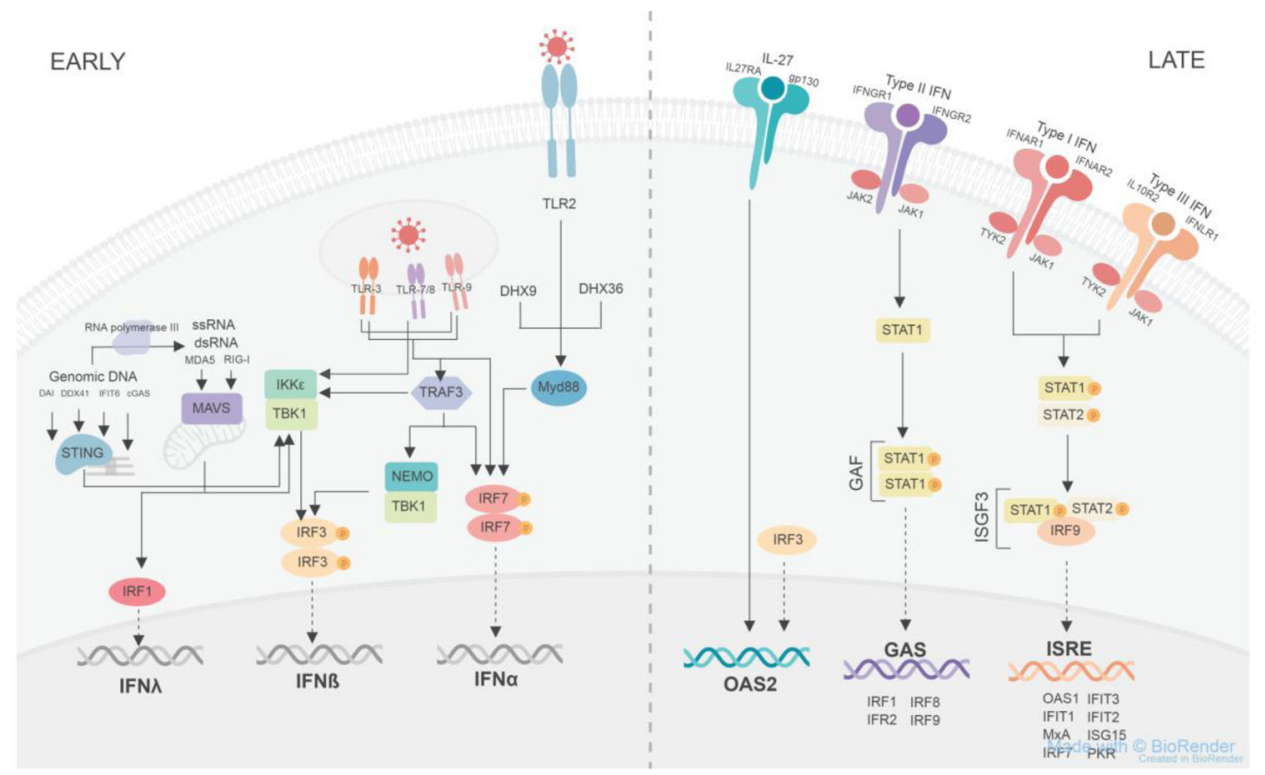

Figure 1, Key Figure. Innate antiviral immunity signaling pathways

In the early phase, viral nucleic acids are recognized by toll-like receptors (TLR) on the plasma and endosomal membranes receptors or within the cytoplasm by melanoma differentiation-associated protein 5 (MDA5), retinoic-acid-inducible gene I (RIG-I), DNAdependent activator of IFN-regulatory factors (DAI), DDX41, interferon (IFN)-induced protein with tetratricopeptide repeats 6 (IFIT6), cyclic GMP-AMP synthase (cGAS), DexHbox helicase 9 (DHX9), DHX36 or TNFa receptor-associated factor 3 (TRAF3). Signaling from TLR2, DHX9, and DHX36 goes through myeloid differentiation primary response gene 88 (Myd88) which stimulates phosphorylated IFN-regulatory factor 7 (IRF7) to homodimerize and enter the nucleus to increase the transcription of IFNa. Signaling from the endosomal TLRs can also stimulate phosphorylated IRF7 homodimerization, while an alternative signaling pathway is through the TANK binding kinase-1 (TBK1) and I $\kappa$ B kinase $\varepsilon(\mathrm{IKK} \varepsilon)$ complex, which stimulates phosphorylated IRF3 homodimerization to induce the transcription of IFN $\beta$. TLR3 can also signal through TRAF3, which induces the phosphorylation of IRF3 via the TBK1 and NF- $\mathrm{kB}$ essential modulator (NEMO) complex. The TBK1 and IKKe complex is also formed in response to genomic DNA binding to DAI, DDX41, IFIT6 and cGAS via STING, which is associated with the endoplasmic reticulum. During the replication of genomic DNA, RNA polymerase III forms single stranded RNA replicates that can be detected by MDA5 or RIG-I. MDA5 and RIG-I also sense viral dsRNA and ssRNA and then bind to mitochondrial antiviral signaling protein (MAVS), associated with the mitochondrial membrane, to stimulate the formation of the TBK1 and IKKe complex or MAVS binding stimulates IRF1 to translocate to the nucleus and induce the transcription of IFN $\lambda$. In the late phase, the cytokine interleukin-27 (IL-27) binds to its transmembrane plasma receptor composed of interleukin 27 receptor A (IL27RA) and glycoprotein 130 (gp130) stimulating the transcription of oligoadenylate synthetase 2 (OAS2) in an IFN-independent manner. An alternative signal to induce OAS2 independent of IFNs occurs via IRF3. Type II IFNs bind to their receptor consisting of IFN $\gamma$ receptor 1 (IFNGR1) and IFNGR2; each subunit is associated with janus kinase 2 (JAK2) on the 
cytoplasmic domain. This activates signal transducers and activators of transcription 1 (STAT1) to become phosphorylated and homodimerize forming IFN $\gamma$ activation factor (GAF). GAF then translocates to the nucleus and binds to GAF site within the promoter region of target genes to induce the transcription of IRF1, IRF2, IRF8, and IRF9. Type I IFNs bind to their receptor composed of IFNa receptor 1 (IFNAR1) associated with cytoplasmic tyrosine kinase 2 (TYK2) and IFNAR2 associated with cytoplasmic JAK1. Type III IFNs bind to their receptor composed of interleukin 10 receptor 2 (IL10R2) associated with cytoplasmic TYK2 and IFN $\lambda$ receptor 1 (IFNLR1) associated with cytoplasmic JAK1. Both type I and III IFNs binding to their respective receptors leads to the formation of the phosphorylated STAT1 and phosphorylated STAT2 heterodimer complex which then conjugates with IRF9 to form the IFN-stimulated gene factor 3 (ISGF3) complex. ISGF3 then translocates to the nucleus and binds to the IFN-stimulated response element (ISRE) site within the promoter region of target genes to induce the transcription of OAS1, IFIT1, myxovirus-resistance A (MxA), IRF7, IFIT3, IFIT2, interferon-stimulated protein of 15kDa (ISG15), and protein kinase R (PKR). 


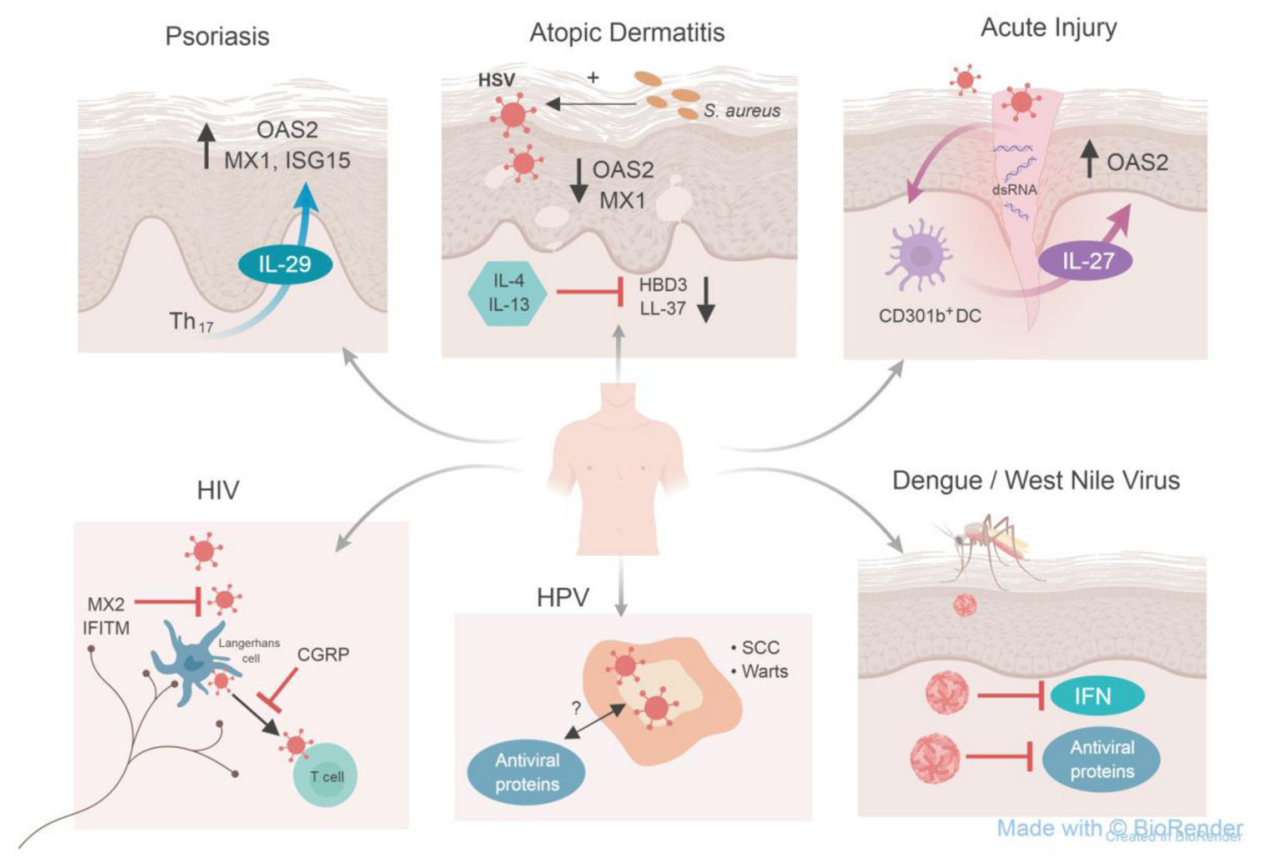

Figure 2. Models of antiviral dysregulation within skin diseases

Antiviral immunity is dysregulated among a broad spectrum of skin conditions (clockwise): Psoriasis is a chronic inflammatory skin condition characterized by high Th17 numbers.

These Th17 cells produce IL-29 which subsequently induces antiviral proteins including OAS2, MX1 and ISG15 [5]. However, innate immune regulators of antiviral proteins in psoriatic skin has not been defined.

Skin affected by atopic dermatitis, also known as atopic eczema, shows increased expression of Th2-type cytokines interleukin-4 (IL-4) and IL-13 which inhibit antimicrobial proteins human beta defensin 3 (HBD3) and cathelicidin (LL-37), which have broad-spectrum antimicrobial activity including antibacterial and antiviral function [54, 113]. AD skin also shows decreased expression of professional antiviral proteins $2^{\prime} 5^{\prime}$-oligoadenylate synthase 2 (OAS2) and myxovirus-resistance 1 protein (MX1). Patients with AD have a defective skin barrier and are frequently colonized with Staphylococcus aureus (S. aureus) which can enhance Herpes simplex virus (HSV) infections via toxin production and enhances viral cell entry and replication [63].

In response to acute mechanical skin injury, double-stranded RNA serves as a danger associated molecular pattern (DAMP) stimulating CD301b ${ }^{+}$dendritic cells (DC) to release IL-27, which induces the production of OAS2 in keratinocytes [7].

The Aedes mosquito transmits many emerging viruses such as Dengue and West Nile virus into human skin allowing these viruses to penetrate permissive epithelial cells including keratinocytes [114-116]. Many viruses produce proteins that are able to counter the actions of interferon (IFN) and antiviral proteins [6, 110, 117].

Human papillomavirus (HPV) causes cutaneous warts and increases the risk of developing squamous cell carcinoma (SCC) typically in immunocompromised patients. Whether this virus is countered by type I or II IFNs or through IFN-independent pathways has yet to be 
determined. Also, the control of potentially oncogenic viruses like HPV and Merkel Cell polyomavirus (not shown here) by antiviral proteins is not well known.

While there is no risk of transmission if the skin is not broken, contact between HIV-infected fluids with broken skin, wounds, or open sores on mucous membranes can lead to HIV transmission. HIV can initially infects the skin, specifically Langerhans cells within the epidermis as well as dermal dendritic cells, which then present HIV antigen to T cells [118121]. Antiviral proteins including $M X 2$ and interferon-induced transmembrane proteins (IFITM) can counter HIV and may be able to prevent the transmission of the virus. Whether the neuropeptide calcitonin-gene related peptide (CGRP) released from neurons promotes proteasomal degradation of HIV within Langerhans cells in the skin, similar to what has been shown in mucosal Langerhans cells [122]is currently unknown and hypothetical. 
Table 1

Summary of AVPs expressed in the skin, their viral targets, and mechanisms of action

\begin{tabular}{|c|c|c|c|c|}
\hline Antiviral peptide & Range of viruses & Viral target & Antiviral mechanism of action & Reference \\
\hline OAS proteins & $\begin{array}{l}\text { RNA and DNA } \\
\text { viruses }\end{array}$ & ssRNA & $\begin{array}{l}\text { Form } 2^{\prime} 5^{\prime} \text { oligomers which activate } \\
\text { RNaseL to degrade viral RNA }\end{array}$ & {$[93]$} \\
\hline OASL & $\begin{array}{l}\text { RNA and DNA } \\
\text { viruses }\end{array}$ & Newly synthesized proteins & ISGylation of viral proteins & {$[103]$} \\
\hline $\mathbf{M x A}$ & RNA or DNA viruses & Ribonucleoproteins or nucleocapsids & $\begin{array}{l}\text { Sequesters viral proteins into } \\
\text { perinuclear complexes, prevents } \\
\text { nuclear translocation of incoming viral } \\
\text { ribonucleoprotein, and blocks viral } \\
\text { transcription and replication within the } \\
\text { cytoplasm }\end{array}$ & [94] \\
\hline $\mathbf{M x B}$ & Retrovirus & Pre-integration complex & $\begin{array}{l}\text { Prevents the pre-integration complex } \\
\text { from uncoating, importing into the } \\
\text { nucleus, and integrating into host } \\
\text { chromosome }\end{array}$ & {$[95,96]$} \\
\hline GBP & $\begin{array}{l}\text { Positive sense RNA } \\
\text { viruses }\end{array}$ & Ubiquitinated replication complex & $\begin{array}{l}\text { Promotes autophagy of ubiquitinated } \\
\text { replication complexes }\end{array}$ & {$[97,98]$} \\
\hline IRG & $\begin{array}{l}\text { Positive sense RNA } \\
\text { viruses }\end{array}$ & Replication complex & $\begin{array}{l}\text { Targets the replication complex using } \\
\text { an ubiquitin-like LC3 conjugation } \\
\text { system }\end{array}$ & {$[97,98]$} \\
\hline IFITM & Enveloped viruses & Fusion to late endosomes or lysosomes & $\begin{array}{l}\text { Blocks viral fusion with cell } \\
\text { membranes }\end{array}$ & {$[99]$} \\
\hline IFIT & RNA viruses & $\begin{array}{l}\text { Lack of } 2^{\prime}-\mathrm{O} \text { methylation or uncapped } \\
5^{\prime} \text { ppp }\end{array}$ & $\begin{array}{l}\text { IFIT1 detects viral RNA and then } \\
\text { forms a complex with IFIT } 2 \text { and } 3 \text { to } \\
\text { sequester the viral RNA from the } \\
\text { replication pool }\end{array}$ & {$[100]$} \\
\hline PKR & RNA viruses & ssRNA and dsRNA & $\begin{array}{l}\text { Stops protein synthesis while } \\
\text { promoting select transactivation of } \\
\text { stress response genes }\end{array}$ & {$[101]$} \\
\hline ISG15 & $\begin{array}{l}\text { RNA and DNA } \\
\text { viruses }\end{array}$ & Newly synthesized proteins & $\begin{array}{l}\text { Uses ISGylation to prevent release of } \\
\text { virus }\end{array}$ & {$[102]$} \\
\hline ADAP2 & RNA viruses & Clathrin-mediated uptake & $\begin{array}{l}\text { Restricts the entry of viruses that enter } \\
\text { host cells using clathrin }\end{array}$ & {$[89]$} \\
\hline \multicolumn{5}{|c|}{ mechanism of action in mice, function in humans unknown } \\
\hline \multicolumn{5}{|l|}{ Abbreviations: } \\
\hline \multicolumn{5}{|c|}{ Oligoadenylate synthetase (OAS) } \\
\hline \multicolumn{5}{|c|}{ Myxovrius resistance proteins (Mx) } \\
\hline \multicolumn{5}{|c|}{ Guanylate-binding proteins (GBPs) } \\
\hline \multicolumn{5}{|c|}{ Immunity-related GTPases (IRGs) } \\
\hline \multicolumn{5}{|c|}{ Interferon-induced transmembrane proteins (IFITM) } \\
\hline \multicolumn{5}{|c|}{ Double-stranded RNA-activated protein kinase (PKR) } \\
\hline \multicolumn{5}{|c|}{ Interferon-stimulated gene 15 (ISG15) } \\
\hline $\begin{array}{l}\text { ArfGAP with dual pl } \\
\text { family of Ras-related }\end{array}$ & $\begin{array}{l}\text { kstrin homology }(\mathrm{PH}) \\
\text { proteins. }\end{array}$ & ins 2 (ADAP2) or centaurin-a 2 (CEN & $\mathrm{s}$ a member of the ADI & (Arf) \\
\hline
\end{tabular}




\section{Table 2}

Viruses associated with skin disease or transmitted via the mucocutaneous barrier to cause systemic infection.

\begin{tabular}{|c|c|c|c|}
\hline Group/Family & Species & Characteristics & References \\
\hline \multicolumn{4}{|l|}{ ssDNA virus } \\
\hline Parvoviridae & Human Parvovirus B19 & Erythema infectiosum ( $5^{\text {th }}$ disease), mild febrile illness with rash & {$[103]$} \\
\hline \multicolumn{4}{|l|}{ dsDNA virus } \\
\hline Herpesviridae & HSV-1, HSV-2, VZV, & $\begin{array}{l}\text { Chronic infection characterized by active phase that forms vesicular lesions } \\
\text { with erythematous base and dormant phase where virus lies quietly within } \\
\text { neurons }\end{array}$ & {$[104]$} \\
\hline Poxviridae & Molluscum contagiosum & Single or multiple flesh colored papules & {$[105]$} \\
\hline Papillomaviridae & HPV & $\begin{array}{l}\text { Warts, Bowen's disease (squamous cell carcinoma in situ), and squamous } \\
\text { cell carcinoma }\end{array}$ & {$[106,107]$} \\
\hline Polyomaviridae & Merkel Cell Polyomavirus & Merkel cell carcinoma & {$[108]$} \\
\hline \multicolumn{4}{|l|}{ Retrovirus } \\
\hline Lentivirus & HIV & Small, circumscribed, round pink/red macules or papules & [109] \\
\hline \multicolumn{4}{|l|}{ ssRNA virus } \\
\hline \multirow[t]{2}{*}{ Flaviviridae } & DENV/WNV & Macules and papules & {$[110,111]$} \\
\hline & ZIKV & Pruritic, erythematous macules and papules & {$[112]$} \\
\hline
\end{tabular}

